\title{
Corporate Real Estate and Competitive Strategy
}

\author{
Bas P. Singer ${ }^{1}$, Bart A.G. Bossink ${ }^{2}$ and Herman J.M. Vande Putte ${ }^{3}$ \\ ${ }^{1}$ Consultant at Re-Creations, Baetenburg 72, 1852 TT Heiloo, The Netherlands, e-mail: \\ b.singer@quicknet.nl \\ ${ }^{2}$ Associate Professor (Corresponding Author) at VU University Amsterdam, Faculty of Economics and \\ Business Administration, Department of Management and Organisation, De Boelelaan 1105, 1081 HV \\ Amsterdam, The Netherlands; e-mail: bbossink@ feweb.vu.nl. \\ ${ }^{3}$ Assistant Professor at Delft University of Technology, Faculty of Architecture, Department of \\ Real Estate and Housing, Berlageweg 1, 2628 CR Delft, The Netherlands; e-mail: \\ h.j.m.vandePutte@bk.tudelft.nl.
}

The paper is published in the Journal of Corporate Real Estate, Vol. 9, No. 1, pp. $25-38$. 


\title{
Corporate Real Estate and Competitive Strategy
}

\begin{abstract}
Purpose - The purpose of his paper is to investigate how organisations use a corporate real estate strategy to support their competitive strategy. It provides a theoretical and empirical overview and analysis of effective combinations of firms' real estate- and competitive strategies.

Design/methodology/approach - The paper constructs a model that integrates three real estate strategies and three types of competitive strategies. Case studies in ten multinational firms in the Netherlands apply the model, and describe and analyse the combinations of the firms' real estate- and competitive strategies.
\end{abstract}

Findings - A standardisation real estate strategy supports all three competitive strategies: lowest costs, differentiation, and focus. A value-based real estate strategy supports a competitive strategy of differentiation and differentiation-focus, and does not contribute to a competitive strategy of lowest costs, or lowest costs-focus. Finally, an incremental real estate strategy is ambiguous, and does not support any of the three competitive strategies.

Originality/value - The paper constructs a literature-based model that combines real estate strategy and competitive strategy. It applies the model in a study of ten cases. Practitioners can use the model to analyse and reconsider the combination of their organisation's real estate strategy and competitive strategy. Academics can use the qualitative research results to design further research that qualifies and quantifies the 
relationship between various elements of real estate- and competitive strategy.

Key words Corporate real estate, Real estate strategy, Corporate strategy, Competitive strategy

Paper type Case study

\section{Introduction}

Many firms explicitly formulate a strategic approach to real estate ( $c f$. Ernst and Young LLP, 2002), and use the portfolio of buildings as an instrument to communicate and reinforce their competitive position in the market (cf. O'Mara, 1999; Krumm, 1999; Roulac, 2001). This article is of interest to those who work for or with these organisations. It searches for answers to the question how corporate real estate strategies support the competitive strategy of an organisation. Although the literature supposes that a corporate real estate strategy is potentially supportive to an organisation's competitive strategy, it does not exemplify and analyse this relationship in-depth. It also does not quantify the coherence between the aspects of the relationship. This article provides an in-depth, qualitative, empirical description and analysis of the relationship between real estate- and competitive strategies. It constructs a literature-based model of corporate real estate strategies and their support to firms' competitive strategies. It uses the model to describe and analyse ten firms in practice, and exemplifies how organisations use a corporate real estate strategy to support their competitive strategy. To practitioners, it gives examples of real estate strategies that support competitive strategies. To academics, 
it provides a theoretical framework within which the relationship between real estate- and competitive strategy can be qualified, quantified, analysed and discussed.

The article is in six sections. This first section presents the central issue. The second section introduces the literature, and the model based on this literature. The third section provides the details of the application of the model in ten cases. The fourth section applies the model in ten large global corporations, with locations in the Netherlands. It describes and explains which combinations of real estate- and competitive strategies the organisations use in their daily practice. The last section ends with a final discussion of the findings and the main conclusions.

\section{Perspectives on a Firm's Corporate Real Estate and Competitive Strategy}

This section combines two ideal-typical models in the literature and constructs a new ideal-typical model. A model on corporate real estate by O'Mara (1999) is the basis of a framework for organisations' real estate strategies, and a model on competitive strategy by Porter $(1996 ; 2004 a-b)$ is the foundation of a framework for organisations' competitive strategies. This section introduces these two models, and then constructs a combined model.

\section{Corporate Real Estate}

According to O'Mara (1999), there are three generic strategies for organisations to pursue in the field of real estate management. To optimise the contribution of their real estate to 
the overall business performance, organisations pursue either an incremental strategy, a value-based strategy, or a standardisation strategy.

An incremental strategy uses space in bits and pieces over time. The more uncertain managers are about their organisation's future, the more they want to delay major commitments until better information is available. Under these conditions, the primary concern of the organisation is to meet the physical requirements of the operations. Organisations implementing an incremental strategy do not put an emphasis on employee amenities or visual aesthetics. It often results in a random collection of various buildings, which most of the times does not deliberately contribute to the expression of an organisation's competitive strategy. Figure 1 symbolises a portfolio of buildings with an ambiguous message. It contains a picture of three buildings, all three varying in dimensions and proportions. Figure 1 also summarises the potential advantages and disadvantages of an incremental real estate strategy. 


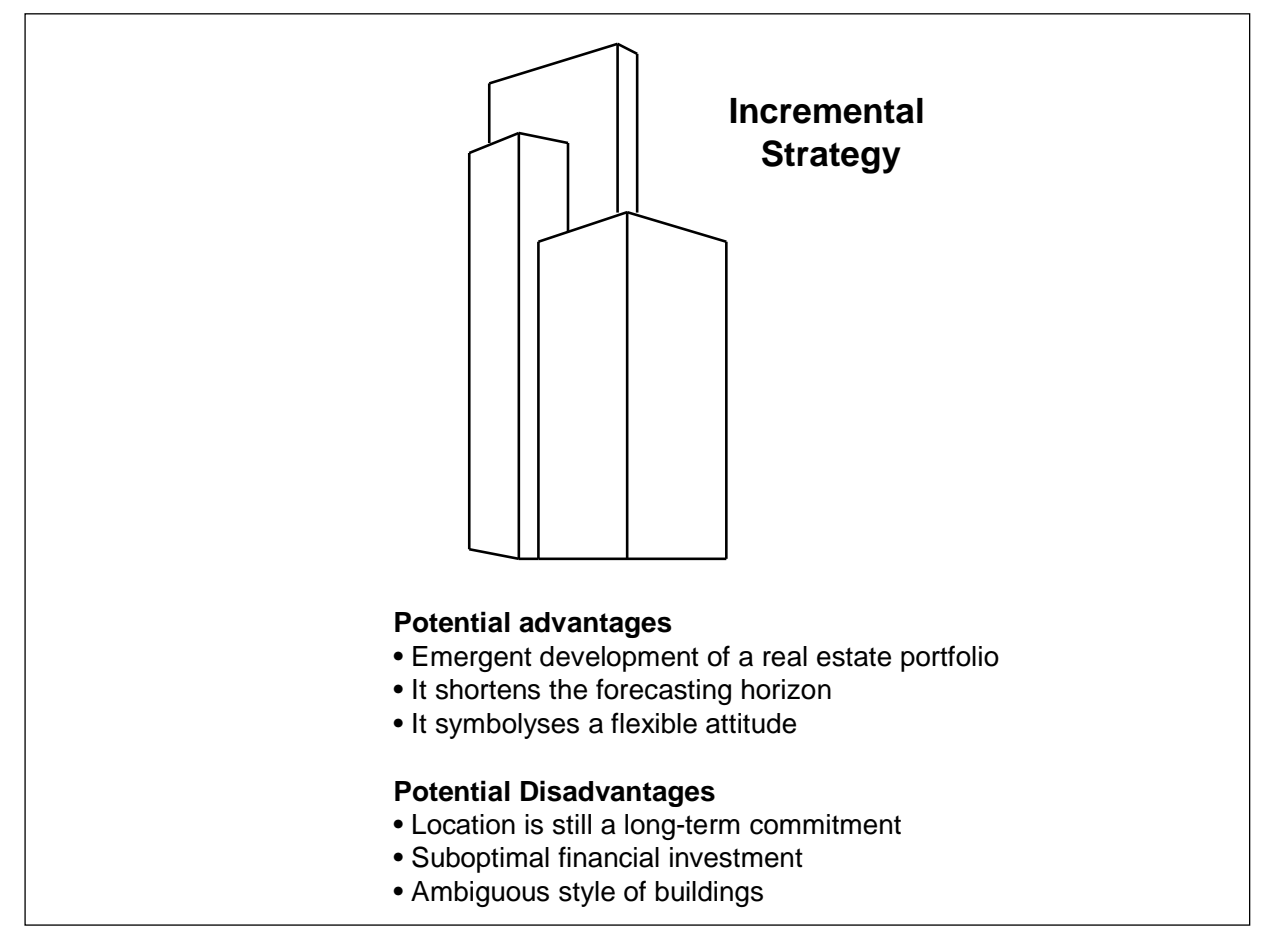

Figure 1. Advantages and disadvantages of an incremental real estate strategy

A value-based strategy deliberately expresses the values and strategic direction of the organisation in its real estate. It highlights both a building's function and meaning to the organisation. It uses the physical setting to symbolise values, and to influence employees' and customers' behaviour. It utilises the buildings' communicative power, and expresses a corporate image. The value-based approach considers the firm's relationship with its customers, employees, and the community, and this is visualised in its corporate objects. Figure 2 symbolises the explicit visual statement of a value-based real estate strategy. It shows a picture of a building with a remarkable and carefully considered design. In addition, Figure 2 summarises the potential advantages and disadvantages of a valuebased real estate strategy. 


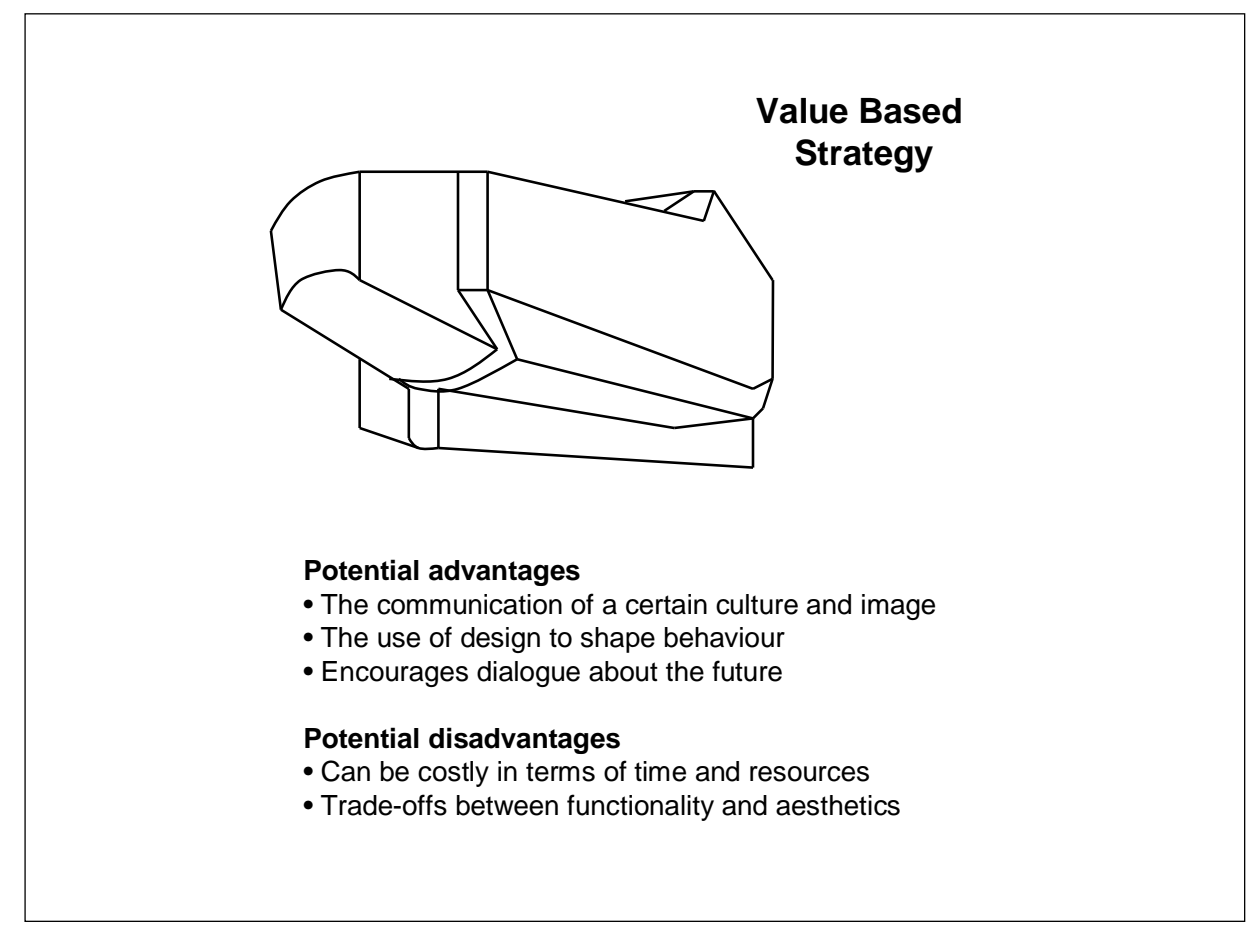

Figure 2. Advantages and disadvantages of a value-based real estate strategy

A standardisation strategy attempts to merely control and coordinate facility design and real estate operations across the entire organisation. It sets standards, and applies them throughout the company. To standardise decision making on real estate and facilities, organisations primarily rely upon predictions about their future facility requirements. A standardisation strategy occupies a great deal of real estate, and a predictable use of the assets is one of its basic characteristics. It focuses on control of business effectiveness, costs, and employees' behaviour. Firms' standardised real estate portfolios are implicit and explicit exemplifications of their rational style. Figure 3 characterises the visual effectiveness-and-efficiency-statement of a portfolio of buildings in a standardisation strategy. It contains a picture of a set of identical buildings. Figure 3 also summarises the potential advantages and disadvantages of a standardisation real estate strategy. 


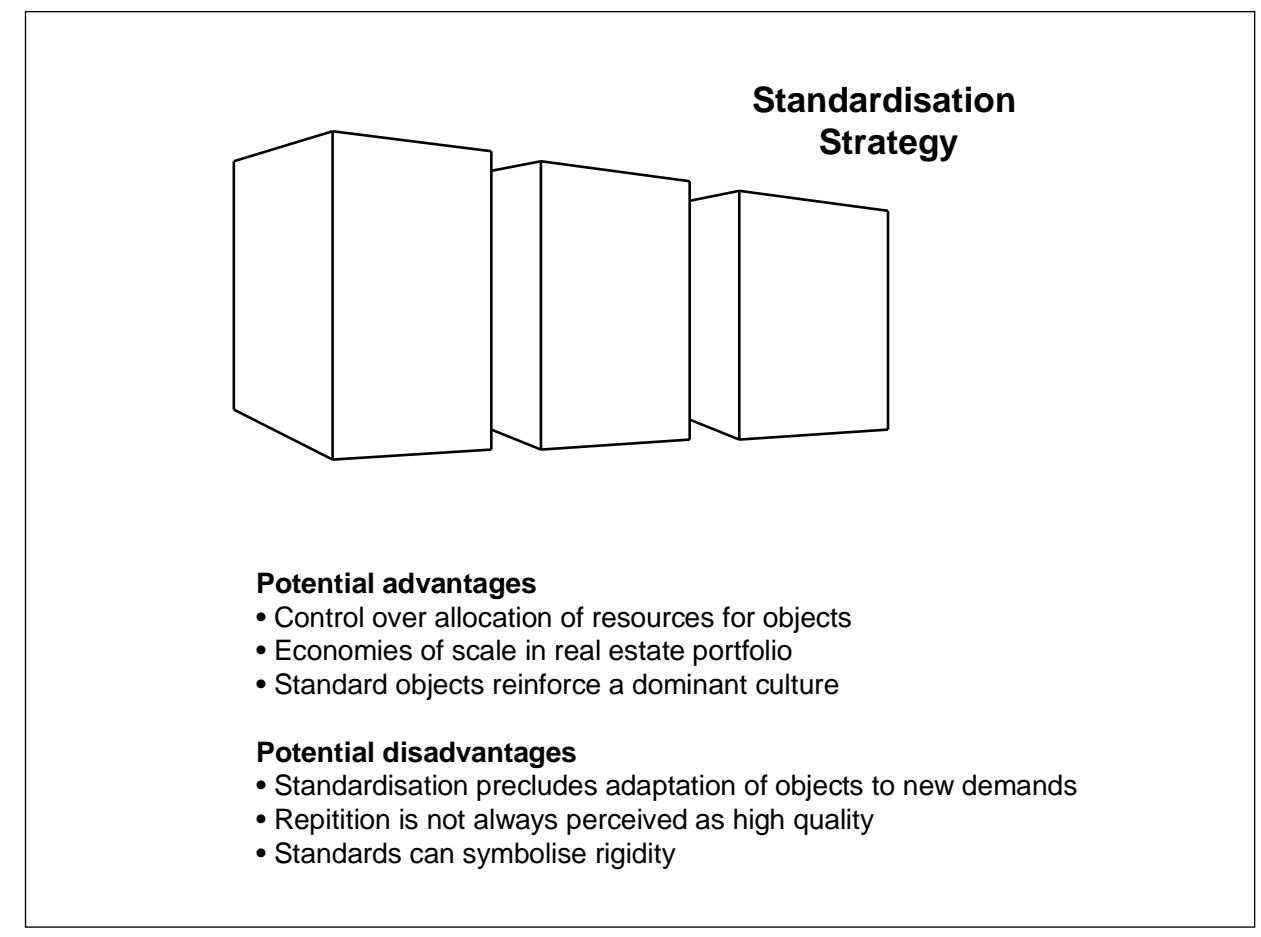

Figure 3. Advantages and disadvantages of a standardisation real estate strategy

\section{Competitive Strategy}

According to Porter (1996; 2004a-b), the fundamental basis of an organisation's performance is called 'sustainable competitive advantage'. Organisations with sustainable competitive advantage have capabilities and competences that enable them to produce services and products the market is willing to buy. Porter distinguishes three generic strategies for sustainable competitive advantage: lowest costs, differentiation, and focus.

An organisation with a lowest costs strategy concentrates on production at the lowest possible costs. It has a broad scope and serves many market segments. The organisation's 
wide scope of markets is often important, because it enables the creation of economies of scale.

An organisation with a differentiation strategy aims to produce and sell unique products and services for a premium price, or a relatively high price. It opts to be unique in its industry. It selects one or more attributes that many buyers perceive as important, and positions itself to meet those needs. Organisations with a differentiation strategy also have a broad scope, and serve a collection of distinctive market segments.

In both a lowest costs- as well as a differentiation strategy, an organisation concentrates on serving a large set of market segments. An organisation with a lowest costs- or differentiation strategy that also concentrates on one target market segment, or just a few defined market segments, performs a focus strategy. There are two variants of the focus strategy: lowest costs-focus and differentiation-focus. The focuser selects a segment in the industry, and tailors its strategy to serving this segment. The focuser wants to achieve a competitive advantage in this particular market segment, and tries to become a specialist.

The matrix in Figure 4 depicts various types of competitive advantage. The matrix consists of four quadrants, successively representing the cost leadership-, differentiation-, cost leadership-focus-, and differentiation-focus strategy. The figure summarises the key characteristics of the three generic strategies. 


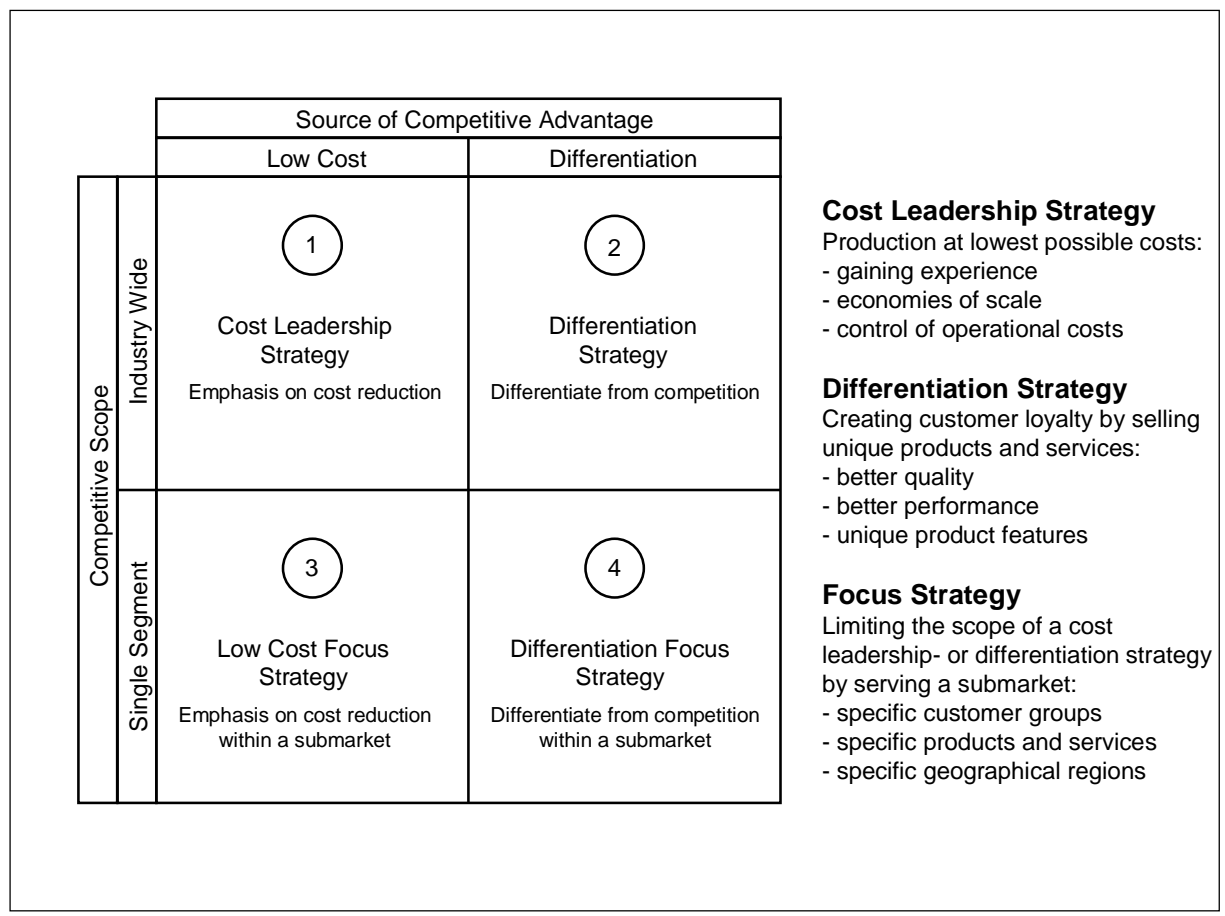

Figure 4. The various types of competitive advantage (Porter, 2004a-b)

\section{The Combined Model for Real Estate Strategies and Competitive Strategies}

A model that combines the frameworks of corporate real estate and competitive strategy typifies a firm's corporate real estate strategy as incremental, value-based, or standardisation, and classifies an organisation's competitive strategy as cost leadership, differentiation, or focus. The combined model symbolises the incremental-, value-based-, and standardisation real estate strategies with the pictures in the first three figures. In addition, it visualises the competitive strategies of lowest costs-, differentiation-, and focus with the basic structure of Figure 4. Figure 5 shows the combined model. The matrix enables the categorisation of a firm's competitive strategy. The three symbols in each quadrant of the matrix symbolise the three possible real estate strategies an organisation can use within these competitive strategies. 


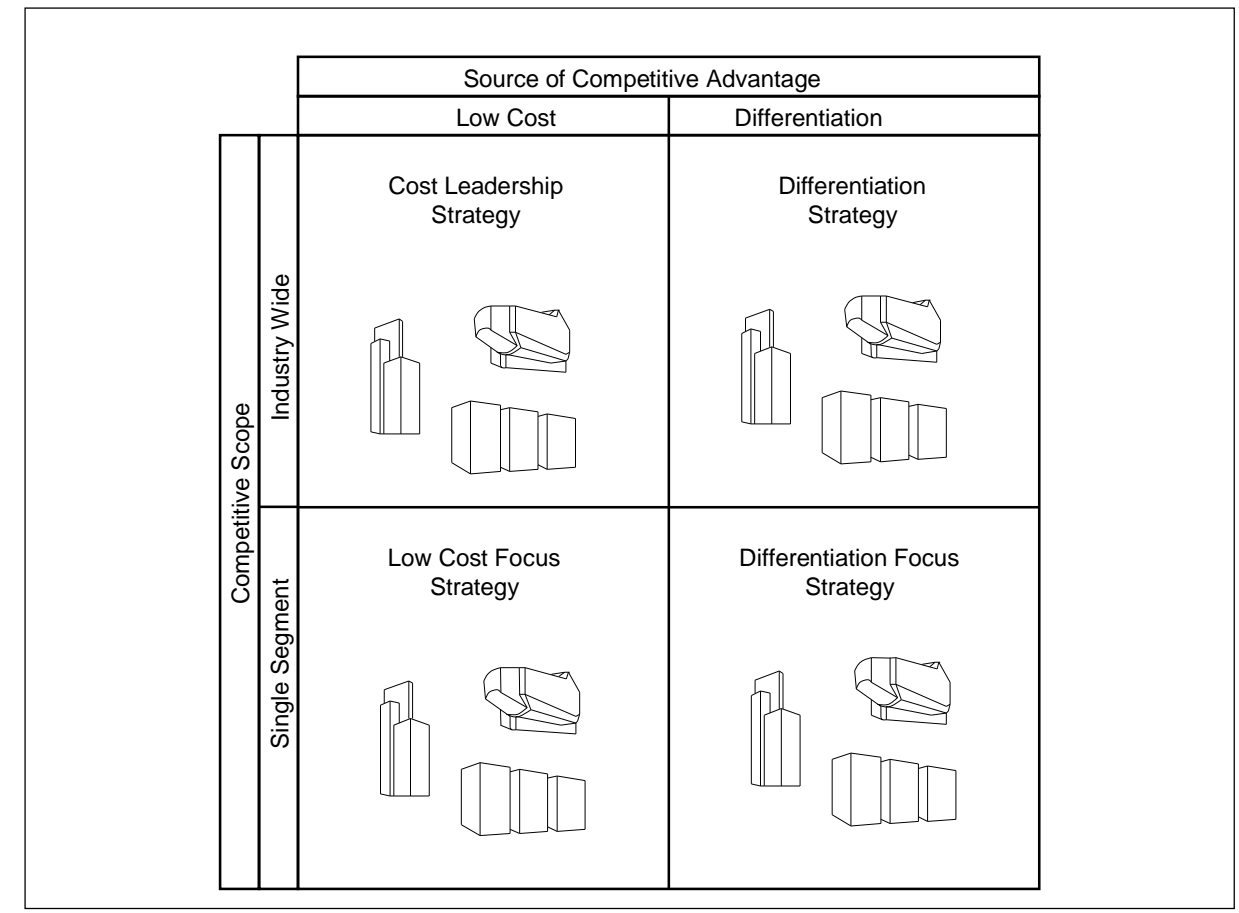

Figure 5. The combined model for competitive- and real estate strategies

\section{Methodology: The Application of the Model in Ten Cases}

The new model synthesises the two perspectives. It enables the study of a firm's combination of a real estate- and competitive strategy in ten cases. This section describes the design of this approach.

\section{Constructing a Literature-Based Model}

In the literature, applied models to study the relationship between an organisation's real 
estate strategy and competitive strategy, with the aim to develop insights into the combination of, and relationship between these strategies are relatively scarce. For this reason, the research constructs a model, which combines O'Mara's (1999) and Porter's (2000a-b) frameworks.

\section{Cooperating Firms and Field Research Method}

The firms that participated in the research project are part of large global corporations, with locations in the Netherlands. The focus of their primary businesses varies from electronics, software, and business services, to insurance, banking, and retail. The first two columns of Table 1 summarise the participating organisations. The firms wanted to be anonymous, and this article refers to them as Alpha up to Kappa.

A case research project studies the firms' real estate- and competitive strategies ( $c f$. Creswell, 2003; Yin, 2004). It consists of interviews with the cooperating firms' real estate executives, and additional document studies. The third column of Table 1 provides an overview of the interviewees.

\begin{tabular}{|l|l|l|}
\hline Organisation & Primary Business/Industry & Function Interviewee \\
\hline Alpha & Banking & Head Portfolio and Asset Management \\
Beta & Retail & Head Facility Management \\
Gamma & Electronics & Manager Corporate Communication \\
Delta & Banking & Manager Real Estate \\
Epsilon & Business Services & Manage Facilities \\
Zeta & Insurance & Location Manager \\
Eta & Computer Hardware & Real Estate Portfolio Manager \\
Theta & Computer Software \& Services & Senior Manager Corporate Real Estate \\
Iota & Business Services & Head Facility Management \\
Kappa & Electronics & Manager Real Estate \\
\hline
\end{tabular}

Table 1. Characteristics of the participating organisations 
Basic themes in the series of interviews were building location, building quantity, tenancy duration, building size/character, building amenities, exterior quality, company space, and communication ( $c f$. Nourse and Roulac, 1993). The document studies consist of annual reports and the firms' policy statements and -outlines.

The case research project constructs an exemplary case description for each participating firm. It focuses on the combination of a firm's real estate strategy and competitive strategy.

\section{Buildings and Competition: Typifying the Firms' Combined Strategies}

The research project studies ten cases, and applies the model in all cases. Figure 6 shows the combination of real estate- and competitive strategies for all firms. This section describes the real estate strategies and competitive strategies of the firms, and analyses the logic behind the combinations. 


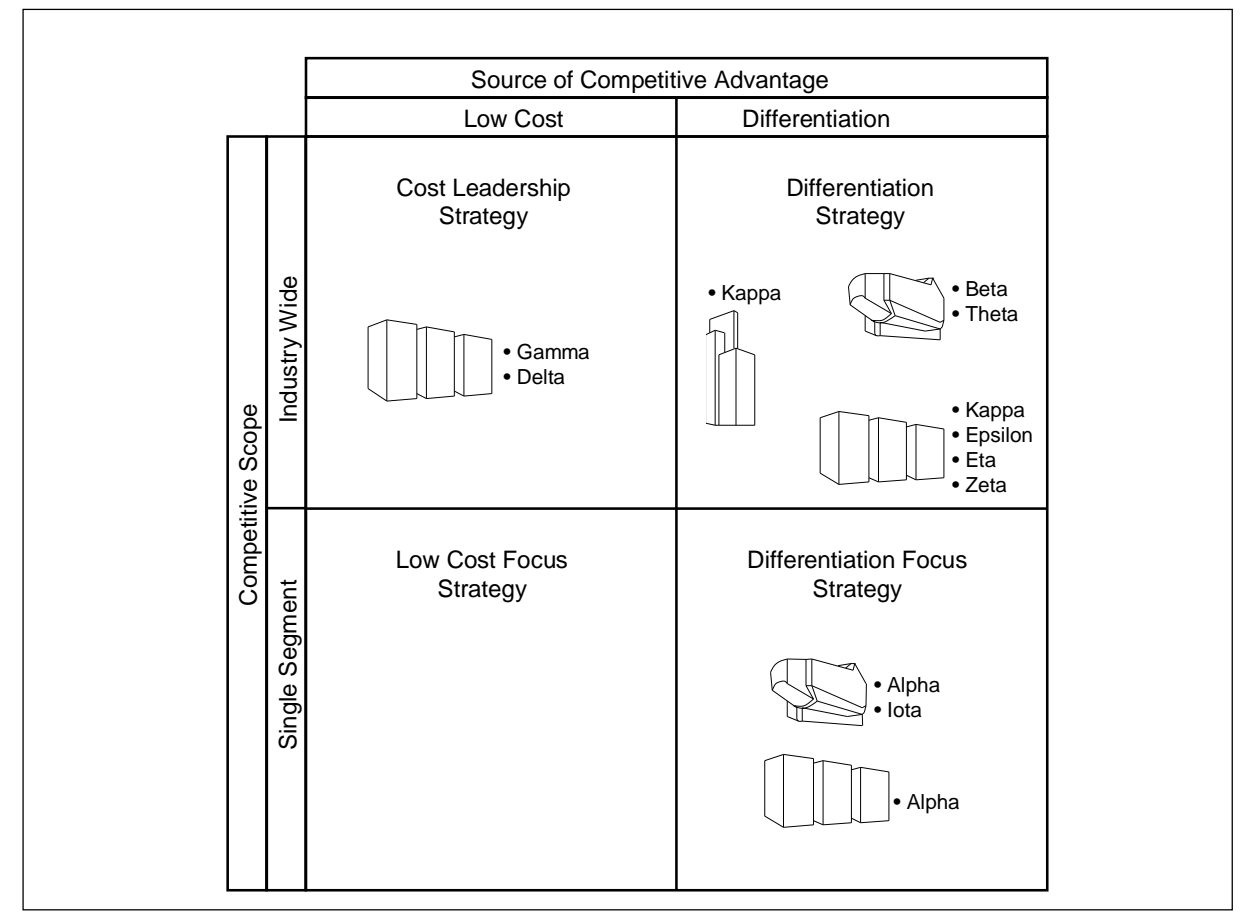

Figure 6. The organisations' corporate strategies and real estate strategies

Alpha - a banking corporation - aims to achieve competitive advantage with a specific combination of products, customers, and geographical markets: "The mix of activities provides us with competitive advantage in the markets and client segments in which we are active," as stated in their 2004 annual report. Alpha has a competitive strategy of differentiation-focus.

The corporate real estate approach is twofold. Productivity and efficiency in the back offices is a mandatory condition to enter the competitive arena. Therefore, Alpha employs a standardisation strategy. To accommodate the back office operations, it acquires easily marketable objects without distinctive visual elements. The corporate real estate approach towards the front office operations is quite the contrary. It supports the marketing objectives of the corporation. Alpha expresses its identity to the public in a 
value-based approach. It invests in the sponsorship of, and in some cases participation in top sporting events. These events align with its corporate culture, in which professionalism, flexibility, and innovation are essential. Alpha, for example, supports this marketing objective by using the façade of its worldwide headquarters as an immense billboard for one of these sporting events.

Alpha combines a competitive strategy of differentiation-focus, with a value-based real estate strategy for its front office, and a standardisation real estate strategy for its backoffice. The value-based approach enables Alpha to establish a high-quality image to their customers, while a standardisation strategy facilitates the control of operational productivity, costs, and procedures.

Beta - a food supplier and retailer - offers a wide range of convenience products to the 'average consumer' in the country. In addition, it wants to become a leading firm in corporate governance: "We are proud to be one of the first Dutch corporations that dedicated a shareholders meeting entirely to corporate governance. Hereby, we have demonstrated that transparency has our highest priority," as stated in their 2003 annual report. Beta operates a competitive strategy of differentiation.

In order to underline the strategic direction, in which transparency of Beta's strategy and operations are important, the corporate real estate portfolio is value-based. Initially, a remote peripheral site, surrounded by a moat, was the location of the corporate headquarters. In order to increase its corporate transparency, Beta decided to move to a site in the downtown area, placing the corporate office in the heart of the community. The building design includes condominiums on top of Beta's office space. To express the 
importance of communication amongst employees, Beta adopted an open space concept instead of the traditional closed cell-offices. It created, for example, additional staircases to stimulate lateral contacts between co-workers.

Beta integrates a competitive strategy of differentiation with a value-based real estate strategy. It wants to create a corporate culture and image, which fits with its differentiation strategy. Beta's buildings emphasise transparency and engagement to both its employees as well as its customers.

Gamma - a supplier of office automation systems - focuses on effectiveness and efficiency to gain competitive advantage. It offers its products and services for a price as low as possible: “... strengthen competitive edge ... by developing highly efficient management," as stated in their 2004 annual report. Gamma wants to increase the productivity of its many clients' business operations, by increasing office automation: "We are ... a provider of comprehensive document solutions that help customers streamline their businesses and cut operating costs," as stated in their 2004 annual report. Gamma uses a competitive strategy of cost leadership.

By adopting a standardisation approach to its corporate real estate, Gamma creates economies of scale in the procurement of office furnishings, and communicates a message of effectiveness and value for money to its clients. Employee workspaces have two shelves of storage space to induce a maximum usage of the firm's digital office solutions. By using the own business operations as a showcase it wants to communicate the possibilities of its products and services.

Gamma unites a lowest costs competitive strategy with a standardisation real estate 
strategy. Initially, Gamma combined a lowest costs competitive strategy with an incremental real estate strategy. During the past years, this strategy transformed into a standardisation strategy due to an improving insight in future real estate requirements. Gamma's portfolio of objects focuses on business effectiveness and cost cutting. The organisation uses its corporate real estate as a means to express its philosophy of the (almost) paperless office.

Delta - a financial services provider - is the head-office of a cooperative bank. It serves as a corporate parent to its local offices throughout the country. Delta emphasises local involvement, personal service, and economies-of-scale: "Market leadership needs primarily to be achieved by strengthening the position of the local cooperatives ... [to realize] best price-quality ratio ... [and therefore] to push back costs," as stated in their 2003 annual report. Delta executes a competitive strategy of cost leadership.

Delta's standardisation approach to real estate exemplifies its cost leadership position. Delta has a central location for its corporate operations. A considerable amount of collective office space expresses Delta's effective use of resources, and horizontal and flat organisation structure.

Delta links a competitive strategy of lowest costs to a standardisation real estate strategy. It wants to increase the effectiveness and efficiency of its buildings, and does not concentrate on the creation of a corporate image with its buildings. Most building decisions focus on the effective- and efficient use of floors, spaces, and resources.

Epsilon - a consultancy firm in finance and taxes - aims to achieve competitive 
advantage by offering a multi-services concept to various types of customers: " $A$ differentiated offer of specializations at the service of larger corporations, and a more integrated offer to smaller clients," as stated in their 2003/2004 annual report. Epsilon works with a competitive strategy of differentiation.

In its approach to corporate real estate, the corporation uses a standardisation strategy. The corporate buildings aim to represent a collective image that covers the large variety of the firm's services. It uses reference images to standardise the exterior- and interior design of the buildings and workplaces. These reference images express the Epsilon brand. Some of the core values these images have to communicate are productivity, reliability, professionalism, functionality, neatness, and modernity.

Epsilon synthesises a competitive strategy of differentiation with a standardisation real estate strategy. It wants to emphasise the constant quality of its multi-services approach with a standardised building concept. The building concept has to support the image of a premium quality brand, and reflects the wide range of products and services the organisation offers to its markets.

Zeta - a financial services provider - puts an emphasis on accessibility. It serves a wide range of customers with various affiliated brands and distribution channels. By offering a diverse mix of products and services, Zeta differentiates itself from its competitors: "Strengthening distribution possibilities ... [through] three strong brands with three different sales channels ... [should be] making us a top player in the market," as stated in their 2004/2005 annual magazine. Zeta has a competitive strategy of differentiation. Its primary activities are mostly non-specific clerical processes. The distribution of products 
and services is the basis of the firm's differentiation strategy.

Zeta uses a standardisation approach to its corporate real estate. Throughout the offices, everyone has identical workspaces, enabling employees to exchange workspaces. Zeta's corporate real estate emphasises the importance of effectiveness and functionality by offering just the necessary, standardised accommodation.

Zeta combines a competitive strategy of differentiation with a standardisation real estate strategy. Zeta's philosophy is that there is no need to propagate its position in the market, because most client-contact is merely indirect, and far away from the organisation's buildings. Zeta also does not use its corporate real estate to create a corporate culture, or an image to communicate to their employees. Its real estate strategy concentrates on creating a work environment that stimulates productivity.

Eta - an information technology company - focuses on offering a wide range of products and services on a global scale. It tries to create synergy, efficiency, and effectiveness between various lines of business in the global marketplace: "We are all about innovation. We are best at creating and delivering differentiated value to our clients," as stated in their 2004 annual report. The Eta competitive strategy is differentiation.

A standardisation approach to Eta's real estate portfolio supports its need for synergy and effectiveness. It developed a series of standard workplaces. The workplace designs fit the requirements of Eta's staff. Employees can subsequently choose which workplace suits best. The use of project-team spaces throughout the office exemplifies Eta's need for synergy and interdisciplinary cooperation.

Eta connects a competitive strategy of differentiation with a standardisation real estate 
strategy. The company has an established brand, and does not use its real estate to enforce its image and brand. Yet, it uses the standardisation strategy to create a culture of productivity, synergy, and mobility to its employees, who are highly skilled and educated.

Theta - a software application developer - serves a wide range of customers with innovative products and services: "Deliver value to customers through a broad set of technologies, designed to complement each other and many third party products and services. This is what we mean by integrated innovation, which is key to our business strategy,” as stated in their 2004 annual report. Theta's competitive strategy is differentiation.

A value-based approach towards their real estate portfolio supports the differentiation strategy. One of the firm's principles is to let innovation arise from the workforce. Theta has a concern for employee wellbeing. It expresses the responsiveness towards employees in an extensive amount of amenities offered, such as childcare, hotel facilities, fitness, dry cleaning, and a basketball court. In addition, the design of the interior is colourful with playful accessories, such as a punching bag and a deck chair. Departments that are more conservative show a rather traditional working environment.

Theta synthesises a competitive strategy of differentiation with a value-based real estate strategy. The organisation heavily invests in providing a high quality work environment for its employees. The value-based real estate strategy focuses on expressing Theta's concern for employee wellbeing, and its willingness to respond to employee needs. 
Iota - a law, civil law notary, and tax advisory firm - gains competitive advantage by creating a distinct profile of itself as an independent, flexible, and gutsy organisation: "Legal firms are generally considered to be quite conservative. [Iota] dissociates itself from this image and aims to emphasize the firm's flexibility and its ability to respond to the dynamic needs of the market," as stated by a representative of the firm. Iota's competitive strategy is differentiation-focus.

Iota integrates a preferred gutsy image in its value-based approach to corporate real estate. Legal firms tend to be quite conservative. Iota deviates from this image by working in a highly transparent building, and by using unorthodox materials and colours for furnishing. To express its differentiation Iota deliberately chooses to occupy accommodations with a clearly discernable building mass.

Iota integrates a competitive strategy of differentiation-focus with a value-based real estate strategy. It wants to express that it represents a dynamic group of professionals. Iota's buildings are transparent through its extensive use of glass, are colourful in its finishing, and tailor-made in its selection of interior elements. The objects intend to disseminate a clear, original, and personal approach.

Kappa - an electrical engineering- and electronics firm - aspires to distinguish itself from the competition by developing innovations and bundling various fields of knowledge and expertise: "The concept ... enables us to offer our customers multidisciplinary solutions. By combining products and systems from different areas of expertise, more complete solutions can be provided," as stated in their 2004 annual report. The competitive strategy of Kappa is differentiation. 
The corporate real estate approach is twofold. Kappa uses a standardisation approach to its corporate real estate at the core locations. To bundle the knowledge and expertise effectively Kappa simulates the use of the same workspace by various specialists. It has a reputation for its distinctive architecture, underlining the technological and innovative image of the corporation. Kappa also has several locations on the outskirts, which are subject to an incremental strategy. In the past years, Kappa entered into various projects, as well as into some take-overs, and this led to an incremental growth of the corporate real estate portfolio. These locations are small, and do not contribute to the organisation's corporate identity.

Kappa primarily combines a competitive strategy of differentiation with a standardisation real estate strategy. Kappa uses its standardisation approach to real estate to create a strong image. The buildings have to fit with the Kappa brand. "Architecture is just as much a reflection of a company as are its employees, products, and services," as the firm states in one of its brochures. 


\section{Discussion and Conclusion}

This article constructed a literature-based model, and applied it to describe and analyse the supportive function of organisations' real estate strategies to their competitive strategies. This final section discusses the main conclusions based on this application, and ends with directions for further research.

The literature supposes that a supportive relationship between an organisation's real estate strategy and competitive strategy exists, but does not provide an in-depth description and analysis of this relationship. To fill this gap in the literature this article presents a research project that focuses on a theoretical and empirical description and analysis of the supposed relationship. It uses three literature-based types of corporate real estate strategies: an incremental-, value-based-, and standardisation real estate strategy. In addition, it distinguishes three literature-based competitive strategies for an organisation: a lowest costs-, differentiation-, and focus-strategy. The research project synthesises the three real estate- and three competitive strategies into a combined model. Within the structure of this model, it studies the real estate- and corporate strategies, and the relationship between these strategies in ten Dutch firms. The case study findings show that most of the organisations, seven out of ten, use a standardisation real estate strategy. The organisations using this strategy have a clear vision on the corporate image they want to create with their buildings. Furthermore, they want to perform efficiently. The combination of creating an image and performing efficiently leads to their choice for a standardisation real estate strategy. The research results show that a standardisation real 
estate strategy is capable of supporting all three competitive strategies, respectively: lowest costs, differentiation, and focus. The findings also show that a considerable number of organisations use a value-based real estate strategy. These firms apply this real estate strategy because it enables them to explicitly visualise and position their competitive strategy, image and brand in the marketplace. The four organisations that use this real estate strategy are aware of its relative high costs, and choose to invest in a selected set of corporate objects. These objects symbolise the image and competitive position of the organisation as a whole. The research results reveal that a value-based real estate strategy primarily supports the competitive strategies of differentiation and differentiation-focus. The value-based real estate strategy has more potential to make a statement than a standardisation strategy because of it explicit emphasis on aesthetics and symbols. On the other hand, a standardisation real estate strategy is applicable to support all competitive strategies, and a value-based strategy is not. A value-based strategy is too expensive to support a competitive strategy of lowest costs and lowest costs-focus. Finally, just one single organisation used an incremental real estate strategy. This firm did not deliberately choose this strategy, but had to adopt it because of several company take-overs. In addition to this, the research results indicate that this real estate strategy does not contribute to the firm's competitive strategy.

Further research that investigates the relationship between real estate- and competitive strategy can be of both a qualitative- and quantitative nature. Further qualitative research can focus on a more in-depth, and detailed analysis of the various combinations of competitive- and real estate strategies. It could zoom in on the organisation as an entity with distinctive departments, systems, objectives, and ethics; and with several distinctive 
combinations of competitive- and real estate strategies, in the same organisation, and at the same time. Further quantitative research can concentrate on the specific factors of real estate strategies and competitive strategies, and on the correlations between the factors.

Overall, this research project reveals that by standardising their buildings or developing some value-based corporate buildings in their portfolio, organisations are able to emphasise their competitive position. Compared with organisations with an incremental real estate strategy these organisations have more potential to to mark their competitive position in the marketplace.

\section{Acknowledgement}

The authors wish to thank Deloitte Real Estate - The Netherlands, for supporting and facilitating the empirical research project.

\section{References}

Creswell, J.W. (2003) Research Design: Qualitative, Quantitative, and Mixed Methods Approaches. Thousand Oaks: Sage, pp. 246.

Ernst \& Young LLP (2002). Views of corporate real estate from the boardrooms of Europe. Ernst \& Young Corporate Real Estate Advisory Services (UK), pp. 8. 
Krumm, P. (1999) Corporate Real Estate Management in Multinational Corporations. Nieuwegein: Arko Publishers, pp. 208.

Nourse, H., Roulac, S. (1993). Linking real estate decisions to corporate strategy. Journal of Real Estate Research, 8(4), 475-494.

O’Mara, M.A. (1999) Strategy and Place: Managing Corporate Real Estate and Facilities for Competitive Advantage. New York: The Free Press, pp. 349.

Porter, M.E. (2004a) Competitive Strategy: Techniques for Analyzing Industries and Competitors. New York: The Free Press, pp. 396.

Porter, M.E. (2004b) Competitive Advantage: Creating and Sustaining Superior Performance. New York: The Free Press, pp. 557.

Porter, M.E. (1996) What is Strategy? Harvard Business Review, 74(6), 61-78.

Roulac, S. (2001) Corporate property strategy is integral to corporate business strategy. Journal of Real Estate Research, 22(1/2), 129-152. 
Yin, R.K. (2004) Case Study Research: Design and Methods. $3^{\text {rd }}$ ed. Thousand Oaks: Sage, pp. 181.

\begin{abstract}
About the authors
Bas P. Singer is a consultant at Re-Creations, Heiloo, The Netherlands. He holds an M.Sc. in Architecture, Urbanism and Building Sciences. He can be contacted at b.singer@quicknet.nl

Bart A.G. Bossink is an associate professor at VU University, Amsterdam, The Netherlands. He holds an M.Sc. in Industrial Engineering and Management, and a Ph.D. in Civil Engineering and Management. He can be contacted at bbossink@ feweb.vu.nl Herman J.M. Vande Putte is an assistant professor at Delft University of Technology, Delft, The Netherlands. He holds an M.Sc. in Architecture and Building Sciences. He can be contacted at h.j.m.vandePutte@bk.tudelft.nl
\end{abstract}

